\title{
Esse cabelo em Luanda, Lisboa, Paraíso: Djaimilia Pereira de Almeida e a experiência do desenraizamento na tentativa de integração
}

\author{
Norma Sueli Rosa Lima \\ Universidade do Estado do Rio de Janeiro
}

\begin{abstract}
Resumo
$\mathrm{O}$ artigo tem por objetivo perceber como os romances Esse cabelo: a tragicomédia de um cabelo crespo que cruza fronteiras, e Luanda, Lisboa, Paraíso, de Djaimilia Pereira de Almeida, tematizam a experiência do preconceito racial em Portugal na década de 1980, após a independência de Angola e do término da ditadura salazarista. Através da escrita autoficcional, do seu livro de estreia, e da ficcional de sua segunda publicação, será observado de que forma a intertextualidade realizada pela autora, entre os seus dois livros e com outras obras, se processou na tematização das perdas de utopias, que culminarão na revisão de discursos políticos que foram processados em Portugal e na África.
\end{abstract}

Palavras-chave: autoficção; ficção; literatura contemporânea; Djaimilia Pereira de Almeida.

\begin{abstract}
The article aims to compare how the novels Esse cabelo: a tragicomédia de um cabelo crespo que cruza fronteiras (This hair: the tragicomedy of curly hair that crosses borders) and Luanda, Lisboa, Paraiso (Luanda, Lisbon, Paradise), by Djaimilia Pereira de Almeida, discuss the experience of racial prejudice in Portugal in the 1980s, after the independence of Angola and the end of the Salazar dictatorship. Through the autofictional writing, her debut book, and the fictional one of her second publication, it will be observed how the intertextuality performed by the author, between her two books and with other works, took place in the theme of the losses of utopias, which will culminate in the review of political speeches that have been processed in Portugal and Africa.
\end{abstract}

Keywords: self-fiction; fiction; contemporary literature; Djaimilia Pereira de Almeida.

Recebido em: 30/01/2020

Aprovado em: 01/09/2020

O título do mais recente livro de Djaimilia de Almeida, Luanda, Lisboa, Paraíso, faz referência ao deslocamento entre as cidades de Luanda, Lisboa e o bairro Paraíso, feito, principalmente, pelos personagens Cartola e Aquiles; a motivação para esse movimento foi a da busca de Papá Cartola por uma cirurgia reparadora para o calcanhar do filho Aquiles. As interessantes intertextualidades realizadas com os nomes desses personagens se fazem com 
as culturas brasileira e europeia; há, por exemplo, alusão ao compositor Angenor de Oliveira - a autora revelou ter escrito o livro enquanto ouvia a canção "O mundo é um moinho", a qual considera "uma peça filosófica, mais do que uma canção". Assim, entende haver no livro "muito da desesperança, da alegria aos soluços, que encontro em canções de Cartola" (GABRIEL, 2019a, p. 6). A outra intertextualidade ocorre na forma de paródia do personagem clássico Aquiles, na atualização do herói para a realidade africana: "O calcanhar esquerdo do filho mais novo de Cartola de Sousa nasceu malformado. O pai deu-lhe um nome helénico, tentando resolver o destino com a tradição" (2019b, p. 9).

A experiência do afastamento de Angola, por conseguinte da África, em meados da década de 1980 no contexto da pós-independência, com a nação massacrada pela guerra civil, é a mesma que a escritora já abordara em seu primeiro livro, Esse cabelo: a tragicomédia de um cabelo crespo que cruza fronteiras, lançado em Portugal no ano de 2015 e publicado no Brasil em 2017. No livro de estreia, a experiência desse distanciamento tem foco na personagem Mila, que é a própria persona da autora ficcionalizada, conforme Djaimilia declarou em entrevista: "As experiências que Mila passa em cabeleireiros são análogas as que eu vivi, embora com algumas alterações" (ALMEIDA, 2017). Através da metáfora do cabelo "inadequado", a personagem questiona parâmetros eurocêntricos de beleza, principalmente por via das reflexões sobre os alisamentos aos quais se submeteu, desde criança, para tentar aproximá-lo do de sua avó, Lúcia.

O tratamento, cuja química abrasiva obriga ao uso de luvas, consistia, segundo me explicaram, em "abrir o cabelo", torná-lo mais maleável. (Essa ida a Sapadores fora, na realidade, precedida de um ensaio singular, perto de casa, na dona Esperança, a cabeleireira da avó Lúcia. Inconformada com o estado do meu cabelo, agarrou num secador e numa escova e, no intervalo de pentear a minha avó, esticou duas madeixas por caridade, para provar que não era um caso perdido. "Estás a ver? Não lhe digo que a Mila tem um belo cabelo? É só esticar um bocadinho e -veja!”. Saímos da dona Esperança de mãos dadas: a minha avó com a mise do costume, eu com umas mechas esticadas um pouco acima das orelhas, que não se pentearam para podermos mostrá-las em casa, ambas tentando esconder a descrença nesta solução milagrosa) (ALMEIDA, 2017, p. 24).

Percebemos que a autoficção viabiliza o jogo entre persona e personagem, o qual produz perspectivas e ópticas processadas em movimento, e não posições subjetivas de observação fixa e de objetos concluídos.

O autor procura, em outras palavras, dar realidade à situação de observação, incluindo o leitor na exposição direta dos fatos, ao mesmo tempo que questiona o perspectivismo cenográfico ao qual a observação está submetida e que afeta a veracidade e confiabilidade tanto do testemunho do autor, do narrador, do personagem, quanto do leitor (SCHOLLHAMMER, 2011, p. 112). 
Mila muda-se para Portugal ainda criança: "Segundo se diz, desembarquei em Portugal particularmente despenteada, aos três anos, agarrada a um pacote de bolacha Maria" (ALMEIDA, 2017, p. 12). É interessante notar que em Luanda, Lisboa, Paraíso, o leitor atento perceberá o diálogo que a autora realiza com a sua primeira publicação, quando alguns personagens são reapresentados com outras configurações. Assim ocorre com o avô Castro e a tentativa de ir a Portugal para operar o filho que nascera com uma perna mais curta do que a outra, que no segundo livro inspirou o protagonista Cartola. Nesse sentido, é pertinente a observação de Karl Erik Schollhammer sobre uma característica do escritor contemporâneo, que "parece estar motivado por uma grande urgência com a realidade histórica, estando consciente, entretanto, da impossibilidade de captá-la [...], em seu presente" (2011, p. 10).

Apesar de ser escritora da novíssima geração, Djaimilia de Almeida já teve suas obras reconhecidas pela crítica: o livro de estreia foi o ganhador do Prêmio Novos, em 2016, e o segundo obteve outros três: o Literário Fundação Inês de Castro, 2018, o Literário Fundação Eça de Queiroz e o Oceanos, ambos em 2019. A representante prestigiada das literaturas de língua portuguesa, curiosamente, é costumeiramente identificada na mídia como escritora portuguesa, apesar de ter nascido em Angola e de tematizar, em suas duas obras, a situação do emigrante angolano em Portugal.

O tema da emigração dos africanos, no contexto anterior ao de 1975 , veiculava a primeira ideia falaciosa de essa mudança territorial auxiliá-los a se tornarem "civilizados", ao serem transformados em "cidadãos portugueses", com os mesmos direitos dos lusos. O avô Castro e o personagem Cartola não se deslocaram para Lisboa no período colonial, pois os enredos os situam na década de 1980, igualmente a motivação inicial de ambos não é a busca pelo mercado de trabalho europeu; entretanto, por conta da demora do tratamento dos filhos, acabam tendo que se fixar em Portugal, nunca mais retornando à África. É essa memória ferida que Djaimilia toca nas duas obras, e apesar de situá-las quando Angola já era nação independente, a mentira do sonho vendido no período anterior é denunciada, principalmente nessas duas personagens que vão para a Europa em busca dos direitos dessa condição.

Vale a pena realizar contraponto com a perspectiva da emigração ocorrida durante o período salazarista em Portugal, pesquisada pela historiadora Heloísa Paulo. Ela investigou o conceito de nação na perspectiva do pensamento fascista, quando o Estado delimitava e controlava a atividade daqueles que o compunham. Neste ambiente, a construção do emigrante português está marcada pelo conteúdo "épico" salazarista, quando "é visto como o 'guardião' dos atributos da nacionalidade, transferindo para o presente a 'predestinação' colonizadora da época dos descobrimentos" (2000, p. 54). Oriundos do meio rural, aqueles emigrantes eram incentivados a manterem as próprias raízes, o espírito da vida aldeã, no encorajamento à sublimação da memória coletiva; perspectiva muito diferenciada do afastamento dos angolanos de sua nação, registrado em Luanda, Lisboa, Paraíso. Não se estimulava a manutenção dos laços de Vó Castro e de Cartola 
com suas raízes africanas, porque perversamente interpretadas como traços selvagens e incultos. No século XX, sabemos, a relação estabelecida entre a metrópole e suas colônias africanas tinha a missão de integrá-las ao "progresso", quando elas receberiam as benesses dessa "evolução".

Eduardo de Sousa Ferreira chamou a atenção para o fato de, na fase em que se constituiu como colonizador, Portugal ter negado que o principal objetivo do projeto colonialista era o proveito econômico daquelas nações, embora a metrópole se beneficiasse de forma evidente de suas riquezas. $\mathrm{O}$ fato colonial era apresentado como consequência secundária, pois segundo Marcelo Caetano o interesse maior dos portugueses pelos nativos seria o "de lhes levar a mensagem do Evangelho, de os libertar das trevas do paganismo e salvar as suas almas" (apud FERREIRA, 1974, p. 138). Haveria sempre o entendimento de que caso os colonos assimilassem a cultura e as técnicas europeias poderiam constituir ameaça à dominação, mas a política de assimilação objetivava unicamente formar uma elite que partilharia dos pontos de vista dos colonizadores, a fim de os auxiliar na destruição da cultura do seu próprio povo.

A Igreja Católica contribuiu para assegurar as vantagens do primeiro caso, sem que fossem corridos os riscos do segundo, colaborando numa aculturação estritamente limitada e controlada; os indígenas recebiam da "cultura branca" e dos princípios cristãos o suficiente para se tornarem obedientes e disciplinados, mas não o bastante para se tornarem hábeis, com um espírito independente e activos (FERREIRA, 1974, p. 139).

A literatura angolana foi um dos instrumentos questionadores dessa tentativa de aniquilamento a partir da década de 1970. Além de ter se constituído como instrumento estético reivindicativo de liberdade, passou a testemunhar a construção nacional (CHAVES, 1999), bem como a refletir os descaminhos da sociedade livre da colonização, mas prisioneira de outros momentos dramáticos, como o da Guerra Civil (iniciada em 1975 e finalizada em 2002), por exemplo. A produção literária contemporânea indica outros descaminhos, como o da especulação imobiliária das empreiteiras que extinguiu casas e edifícios históricos com a finalidade de modernizar Angola, porém sem resolver os seus quadros estarrecedores de desigualdade social. “[...] na pequena casa de sempre, ameaçados de serem desalojados porque um grupo poderoso de financeiros queria construir um grande prédio no terreno, $[. .$.$] a febre de construção tomou$ conta” (PEPETELA, 2014, p. 20). Recentemente, José Eduardo Agualusa escreveu crônica em jornal brasileiro que tematizou os resultados de investigação realizada por 120 jornalistas, de 20 países, com as conclusões sobre os negócios empresariais desonestos de Isabel dos Santos, filha do líder do Movimento pela Libertação de Angola (MPLA), José Eduardo dos Santos. Tendo sido o partido que libertou Angola da situação colonial, é pesaroso os rumos que seguiu, e essa situação pode ser exemplificadora da decepção e das perdas de utopias, quando empresários "criaram com ela todo o tipo de empresas, sabendo muito bem que aquele dinheiro fora roubado ao povo angolano" (AGUALUSA, 2020, p. 6). 
Em paralelo às publicações de autores que denunciam os desvios do projeto inicial de nação livre e justa, há os que têm revisitado períodos recentes da história. Em primeira pessoa com tons de escrita autoficcional, Esse cabelo inicia a narrativa informando que a mãe da personagem Milia cortou, pela primeira vez, o seu cabelo, quando ela ainda contava a idade de seis meses, "o cabelo, que segundo vários testemunhos e escassas fotografias era liso, renasceu crespo e seco" (ALMEIDA, 2017, p. 9). Logo nas primeiras páginas, o leitor é informado de que "descendo de gerações de alienados [...]. A família a quem devo este cabelo descreveu o caminho entre Portugal e Angola em navios e aviões, ao longo de quatro gerações". No final do romance, temos a indagação: "Se o cabelo é a pessoa e eu a travessa, se sou o objeto enfeitiçado, se foi a mim que encerrei na vitrina e na esperança de assistir de camarote ao nosso cinema, quem é ainda a Mila?” (ALMEIDA, 2017, p. 143). A pergunta reflete a própria investigação de identidade diante dos impasses de alteração da aparência física, consequência da condição assimilada que percorreu, por longo tempo, a sua família.

Sem a intenção de constituir as suas obras como "romances históricos", no rastro de autores que a antecederam, Djaimilia Pereira não se preocupa com o compromisso de testemunhar a forma como a nação angolana se ergueu dos séculos em que foi colonizada, mas sim a de perceber os dramas pessoais de exclusão a determinados espaços, nos quais os sujeitos que neles transitaram por quatro gerações acreditaram ou desacreditaram pertencer. Com Linda Hutcheon podemos verificar que Djaimilia reapresenta o passado em seus escritos revelando-o no presente, impedindo-o de ser conclusivo e teleológico, pois tanto a ficção quanto a história são sistemas culturais de construções ideológicas (1991). Também nos auxiliam as reflexões de Schollhammer quando observa que

[...] vemos alguns escritores trazendo, para dentro de suas ficções, as condições factuais de criação, ou o material nitidamente autobiográfico que a envolve, tirando proveito da tensão entre o plano referencial e o plano ficcional, ora para confundir os limites entre essas instâncias, ora, como parece ser a tendência que prevalece, para inserir índices de um real originário na experiência íntima que ancore a ficção de maneira mais comprometida (2011, p. 114).

Em seu livro de estreia, portanto, a cabeleira da personagem-autora atravessa processos que buscam desde os padrões de beleza europeu à constatação do preconceito e do reencontro da personalidade africana. As suas memórias ficcionalizadas podem ser compreendidas como mensagem de ressignificação dos estereótipos e das ideias falaciosas que nortearam a colonização de Angola. Leyla Perrone-Moisés observa que falar de si mesmo por escrito mais do que intencionar recontar a própria história é comunicar-se com um leitor virtual, por isso a autoficção não pode ser percebida como egoísta e descartável, ainda mais no romance autobiográfico analisado, no qual existe a fala de um eu "que se busca e se autoquestiona com 
honestidade" (2016, p. 212). Os dois romances de Djaimilia de Almeida, enfim, se harmonizam com o conceito de narrativização percebido como uma forma essencial para a compreensão humana, quando a narratividade evidencia a "realidade" conforme seja produzida e mantida por suas representações culturais (HUTCHEON, 1991).

Se no primeiro livro podemos identificar a mistura entre memória, imaginação e crítica social tecidas com humor e leveza, que disfarçavam para o leitor a tragédia do personagem ser um cidadão português sem a contrapartida do reconhecimento dessa condição, o subsequente assume tom mais dramático, ainda que contenha forte teor poético e alguma ironia. No próprio prólogo de Esse cabelo, encontramos a crítica:

Testemunhas afiançam-me que sou a mais portuguesa dos portugueses da minha família. É como se me recebessem sempre com um "Ah! A França! Anatole, Anatole!" [...] Escrever tem pouco que ver com imaginação e parece-se com um modo de nos tornarmos dignos de não recebermos resposta. A nossa vida é inundada todo o tempo por essa família taciturna - a memória - como Thatcher temeu que a cultura da Inglaterra fosse inundada pelos imigrantes (ALMEIDA, 2017, p. 8).

A caracterização da autora é feita por considerações que a interpretam ora como portuguesa, ora como mulata, na indefinição prevista para o entre-lugar da diversidade, que precisa ser catalogada, como ensinou a classificação para raças do século XIX:

E no entanto, o meu cabelo [...] é o que me liga diariamente a essa história. Acordo desde sempre com uma juba revolta, tantas vezes a antítese do meu caminho, e tão longe dos aconselhados lenços para cobrir o cabelo ao dormir. [...] Em tempos disseram-me que sou "uma mulata das pedras", de mau cabelo e segunda categoria (ALMEIDA, 2017, p. 13).

Ao trazer o tema do cabelo étnico para a centralidade do romance, a narradora afirma que só é possível escrever sobre essa experiência na medida em que ela se coloca como problemática porque evidencia outra questão: a da sua exclusão em Portugal, na medida em que, apesar de ter a pele clara, possuía a marca africana de um cabelo "difícil". Ela consegue, assim, colocar em debate o discurso enganoso de privilégio para o assimilado, situação simbolizada principalmente através do personagem Castro, que entoava, apenas para dentro, cânticos bakongo:

[...] o portuguesão, como ficou conhecido na juventude, que proferia "centra a bola, seu macaco" referindo-se a futebolistas negros e dividia as pessoas por espécies de animais da selva, caracterizando-se a si mesmo "o tipo macaco". [...]

Viera para Portugal em oitenta e quatro com o intuito de tratar um dos seus filhos, nascido com uma perna mais curta do que a outra, num hospital de Lisboa A perna exigia cuidados médicos inexistentes em Angola. Não veio por isso enquanto imigrante, para trabalhar, mas como pai, acabando por ficar mais tempo do que o previsto e depois ao ritmo das operações e da fisioterapia, até o fim da sua vida. [...] A entrada da Pensão 
Covilhã, mesmo na esquina da Casa de Amigos de Paredes de Coura, os doentes tomam um ar de Lisboa. Trazem um penso num dos olhos, uma gangrena na coxa, o braço guardado num gesso já puído e tatuado, sob o qual se coçam com um pauzinho chinês. São os despojos do império, Camões de ocasião embora tenham apenas nove anos, escusados à mortalidade infantil para que lhes parecem umas férias urbanas e, à semelhança de todos, destinados a conhecer de Portugal, com alguma sorte, apenas o mundo de onde vieram (ALMEIDA, 2017, p. 12-19).

A sensação de invisibilidade do imigrante africano em Portugal é retomada em vários momentos do livro, no retrato da falsa aliança cultuada no tripé "progresso/sanitarização/ desenvolvimento". Na busca pela integração, o avô de Milia guardava canetas Parker de imitação na expectativa de ascensão social, enquanto a alusão aos maus odores existentes nos espaços de exclusão, nos quais as personagens deslocadas transitavam, são constantes nas duas obras.

[...] amarradas com uma guita e oxidadas. Vinha preparado para compromissos, assinaturas, contratos, quando o esperavam anos de um lavabo partilhado, anos sem uso para aftershave. Volvida uma década, sairia da Covilhã para São Gens, um bairro clandestino nos arredores de Lisboa, mandando vir de Angola a mulher e outros filhos, guardando as mesmas malas por desfazer sob uma nova cama, numa casa que também cheirava a mala velha (ALMEIDA, 2017, p. 21).

Luanda, Lisboa, Paraíso, como já foi observado, dialoga com os antepassados de Djaimilia e de Milia, trazendo-os para um segundo ambiente ficcional, através da incorporação de imagens como a da mala velha do Vô Castro, repleta de projetos não realizados. Papá Cartola, apesar de apresentado no parágrafo que abre o romance de modo exultante, percorrerá a mesma trilha de decepção.

O ponto alto daqueles anos foi o casamento de Severino, pedreiro da obra, um órfão de dezanove anos que convidou Cartola para padrinho. De camisa lavada e casaco de bombazina escovado, o Papá foi o soba da cerimônia, à qual emprestou a solenidade de um patriarca. Despejou no cabelo meio frasco de água-de-colônia. Esfregou a testa com manteiga de cacau. Até afiou a navalha para fazer melhor a barba (ALMEIDA, 2019, p. 7).

A afirmativa "vale mais nascer grego em terra de troianos do que nascer gazela em terra de leões", ao erguer o menino no dia em que Aquiles foi batizado (ALMEIDA, 2019, p. 9), faz menção ao desejo de destino másculo para o filho de Cartola, quando gazela nomeia, de forma pejorativa, o homossexual masculino, ao mesmo tempo que denota animais extremamente velozes. O batismo com o nome do herói grego ironiza a impossibilidade do menino adquirir a velocidade do semideus Aquiles, que segundo a lenda a ganhou quando foi salvo da fogueira pelo pai Peleu. Como se sabe, ele fora jogado nela pela própria mãe, a deusa Tétis, que assim 
costumava fazer com os filhos tidos da sua união com um humano. Como teve chamuscada a boca e queimado o osso do pé direito, Centauro Quíron, hábil na arte da medicina, foi chamado para substituir o osso queimado pelo do gigante Dâmiso, que em vida fora um corredor extremamente veloz (GRIMAL, 2000, p. 35-36). Na obra por nós analisada, entretanto, nenhum médico europeu conseguirá tornar o Aquiles africano quase um deus de perfeição.

Esse episódio mitológico foi retomado por outros poetas que recriaram a figura do guerreiro, tentando contemplar o percurso da sua vida na invenção de episódios que preenchessem as lacunas dos relatos homéricos. Dessa forma, foi-se criando pouco a pouco um ciclo de Aquiles sobrecarregado de vários enredos, frequentemente divergentes, e que inspirou os poetas trágicos e épicos de toda a Antiguidade, até à ópera romana. Djaimilia é a voz contemporânea que se une a de tantos outros para ressignificar Aquiles agora em Angola, porém o dessa versão já não deseja, ou não pode ser, personagem de um épico, como veremos mais adiante.

Ao partir para Angola a fim de tentar a cura do filho quando ele já está com a idade de quinze anos, Cartola se vê engendrado na exclusão. Deixa a esposa Glória, acamada desde o parto do menino, em sua terra natal para as quais nunca mais regressará. Ele e o adolescente chegam a uma Lisboa que tinha sido, primeiramente, apreendida pela imaginação da então criança Aquiles, quando

gastou cinco sebentas de papel-manteiga a desenhar e redesenhar Lisboa. O Tejo banhava a Baixa, fustigada por um dilúvio colorido a lápis de cera azul-vivo. Aqui e ali, avistavam-se porta-aviões desenhados ao pormenor a esferográfica. Além, um submarino era regido por espiões vietnamitas e, perto do lugar onde à escala ficariam as Avenidas Novas, uma longa linha de coqueiros sombreava famílias de passeantes em biquíni que piquenicavam à sombra entre cavalos brancos, ambulâncias, focos de incêndio e macacos com cara de homem, Os rascunhos, amarrotou-os e atirou-os para dentro de um jerricã esquecido na varanda da cozinha, que um dia a irmã encheu de água fazendo-os assomar como barquinhos naufragados (ALMEIDA, 2019, p. 17).

Ao chegarem ao aeroporto, ninguém os esperava para ouvir a fala africana treinada a assumir tons que a identificasse como a de um autêntico lisboeta. Lisboa parecia-lhes pequena e escura; entretanto, "era Portugal" (ALMEIDA, 2019, p. 27). A metáfora da chuva é constante para a descrição da cidade, metonímia da própria Europa fria, distanciada do sol e da luz constantes como emblemas da África. A recepção da Pensão Covilhã cheirava a mofo e a "janela americana enferrujada abria-se para um muro e um contentor do lixo" (ALMEIDA, 2019, p. 28).

O personagem Barbosa da Cunha, português obstetra com quem Cartola trabalhara como assistente em Angola, garantiu que o ajudaria a obter os documentos que the outorgariam o reconhecimento de cidadania portuguesa; entretanto, isso nunca ocorreu. $\mathrm{O}$ fato é a representação do logro da antiga promessa salazarista que intentou disfarçar a relação opressora e exploratória com as suas colônias. 
Confiou o pedido da nacionalidade portuguesa a Barbosa da Cunha passando-lhe para a mão uma pasta com papelada que não voltou a ver. Pelo menos uma vez por ano, assegurava a Aquiles que os documentos estavam para sair. [...] Não contava a ninguém que não sabia em que pé estava o processo, de que o obstetra pouco ou nada falava. Vivia com medo da polícia. [...] Parecia pensar que um dia lhe bateriam à porta e the diriam que estava tudo tratado, que era enfim português, direito que julgava pertencerlhe. Não sabia ele [...] a origem etimológica da palavra Tejo? (ALMEIDA, 2019, p. 74).

A pergunta que finaliza o trecho citado é chave para a compreensão do desfecho da trama, como veremos mais adiante. O significado do vocábulo Tejo é impreciso, podendo ter derivado do hidrotopônimo latino Tagum, de um étimo pré-romano incerto, ou mesmo exprimir jogo em que se atiram moedas a uma faca fincada no chão. De qualquer modo, a partir da instalação de pai e filho e de suas permanências em Lisboa, haverá sucessão de perdas, decepções, invisibilidades e exclusão, que culminará com o incêndio da humilde casa alugada por eles no bairro Paraíso.

O romance traz outros personagens significativos, como o espanhol Pepe. O emigrante surge no capítulo vinte e dois descrito como casado com a transmontana Floripes, que lhe dera o filho Amândio, com o qual ele não se entendia. Estabelecido em Lisboa desde a década de 1940, oriundo de aldeia pobre, viu serem assentadas as primeiras casas da Quinta do Paraíso. Seu cão de nome Tristão apresenta outra intertextualidade com o personagem emblemático de Tristão e Isolda, cuja origem possivelmente seja a de uma lenda celta do século IX. Também Tristão, como Aquiles, tem motivado uma infinidade de versões e de recriações ao longo dos tempos.

Pepe viera da Galiza [...] Embriagado, Pepe acordava do registo carismático para um plano paralelo em que os sons da floresta cortadas pela sua respiração ampliada o balançavam num compasso de loucura. Então, erguendo-se, dançava de braços abertos como um carnavalesco triste, fugia dos pinheiros, falava sozinho, ria de sombras, enquanto o cão dormia a sono solto em cima das mantas imundas, guardando-o dos seus delírios como uma boia de realidade à qual se agarrava ao aterrar de cansaço, até adormecer ao relento, como um Thoreau arrebatado.

Cartola apanhou Pepe sem réstia de esperança, mas este viu nele uma vocação sofredora e digna como sentia ser a sua (ALMEIDA, 2019, p. 87-92).

Comparado com Henry David Thoreau, Pepe adquire contornos humanistas, quando sabemos que Thoreau foi filósofo, literato à margem de sua época, precursor pioneiro da ecologia pela integração que fazia entre a arte e a natureza, além de ferrenho defensor dos direitos civis. $\mathrm{O}$ fato do personagem ser originário da Galiza merece que busquemos o auxílio de José Hermano Saraiva, quando o historiador alerta para o fato de, na busca pelos mais antigos vestígios da formação do que hoje se constitui como Portugal, uma das certezas quanto à origem de seu povoamento é a de que nenhuma foi autóctone: "O povo português resultou 
assim de um milenário processo de miscigenação de sangue e de sucessivas sobreposições culturais" (1999, p. 21), embora a colonização romana tenha atenuado as diferenças étnicas. A criação e o desenvolvimento do Condado Portucalense não possuem registros, sendo comum encontrarmos, nos historiadores, a mesma postura observada em Saraiva, que assinala, em vários momentos, esta imprecisão:

São raros os documentos escritos e deixou de existir legislação geral. [...] Muitos autores têm procurado resposta para esta pergunta: a partir de que momento se deve considerar que Portugal foi um Estado independente? A dificuldade que todos sentiram em encontrar uma solução resulta de que a independência portuguesa não se verificou, como acontece com os Estados modernos, num momento determinado e politicamente bem definido (SARAIVA, 1999, p. 41-45).

Até se tornar independente, Portugal pertencia à Galiza, como afiança o historiador: "Nesta imprecisão política aparece com frequência o nome da Galiza, que chega a ser um reino e outras vezes tem categoria de condado" (SARAIVA, 1999, p. 42). Vários séculos depois, verificamos que a atual condição dessa comunidade é precária, comparativamente à de outras regiões da Península Ibérica, pois o seu desenvolvimento agrícola se encontra ainda bastante atrasado; por essa razão, ela tem exportado mão de obra para outros países. Os destinos de Pepe e Cartola se unem na dramática situação de transplantados; a relação entre eles, inclusive, se desdobrará em amizade com tons homoafetivos. Ao escrever sobre o novo amigo com alegria para a esposa Glória, nas costumeiras e disfarçadas cartas que escondiam a real situação de penúria por que passavam, ela reagiu:

Como é mesmo o nome desse senhor? Pepe?! Pepe em espanhol? Mas é cubano? Sim. Hum, não sei, não fica a dar muita conversa nesse senhorzinho. Uma pessoa tem de ter cuidado, que esses brancos não são de confiança. Lembra lá em Moçâmedes aquele homem do talho? São mesmo gatunos, querem só chegar perto de uma pessoa, depois ficam a falar à toa que esses pretos isto, esses pretos aquilo e são angolanos são quê, Papá, promete que não fica a dar confiança à toa nesses cubanos daí. Você saiu mesmo só daqui e eu nem tou aí. Depois vem dizer que surgem problemas, que só querem dinheiro. Espera só até eu chegar aí e podermos montar a nossa casinha. Conta ainda como é a casa, tem cama de casal? Ah, tem? É mesmo nessa cama que vamos fazer nosso menino, Papá, o nosso filho prometido que Deus mesmo vai-me dar um dia, o meu Deus pode todas as coisas. Aquece bem o meu lugar, Papá, tá bem? As minhas pernas estão a melhorar [...] E cumprimentos no dr. Barbosa da Cunha, isso é que são grandes amigos já desde o tempo colonial, fico só a lembrar eles bem finos a servirem o jantar... quando eu chegar aí vai ser assim, maionese, refresco, isso tudo, Papá, tá, beijo, beijo! (ALMEIDA, 2019, p. 102).

No diálogo estabelecido entre os personagens de Esse cabelo com Luanda, Lisboa, Paraíso, que estamos realizando aqui, é interessante notar que Vó Castro leva a esposa para 
Lisboa, o que não acontecerá com Cartola e Glória, para os quais não se efetivará o slogan "felizes para sempre", costumeiramente citado por ela nas correspondências enviadas ao marido. Através de "cartas e telefonemas, Cartola alimentava as esperanças da mulher como quem rega o canteiro de flores de uma sepultura" (ALMEIDA, 2019, p. 105). A descrença de Glória no caráter de Pepe e a cega confiança no dr. Barbosa, que nada fez por Cartola em Lisboa, ilustram a ilusão com os poderosos e o afastamento daqueles pelos quais se deveria nutrir a solidariedade, que os uniria pela condição marginal.

A relação entre Cartola e filho se deteriora em Lisboa, principalmente após o incêndio em que perderam a casa. Aquiles passa a culpar o pai por "seu mau hábito de chegar a casa bêbedo depois de serões à porta que ao filho pareciam rodas de ilusão, um entretém de mortos parados no tempo" (ALMEIDA, 2019, p. 151). Distanciado da imagem épica, Aquiles era "um homem vindo de algum lado a caminho de alguma parte, 'o Aquiles, aquele preto coxo'" (ALMEIDA, 2019, p. 151), destituído de valores nobres. Ele ilustra o distanciamento do que Mário César Lugarinho compreende como "a formação de paradigmas que dão sentido e forma às identidades masculinas nas literaturas dos PALOPs, herdados das tradições autóctones e do colonialismo, ou formulados como projetos de ruptura" (2017, p. 141), por principalmente evidenciar o não compromisso com a masculinidade épica que teceu a construção do "novo homem".

Esse discurso desenvolvido durante a guerra colonial pretendeu forjar o africano em antítese ao colonizador branco na explicitação em suas qualidades de valentia e bravura. A ficção contemporânea revê essa condição, na perspectiva da sociedade angolana que vê as suas utopias desaparecerem, pois agora já não há a imagem forjada em perspectiva revolucionária, mas a projeção das fragilidades em contrapontos com masculinidades. Assim é que encontramos Aquiles durante longo período da narrativa inerte, deitado em um leito a se preparar e a se recuperar de cirurgias, como a sua mãe imobilizada em sua cama de Angola; ele herda o seu lugar de subalternidade e de imobilização na pretensa mobilidade realizada entre Luanda, Lisboa, Paraíso, na aproximação entre masculino e feminino.

Desse modo, está distante tanto da percepção épica grega do Aquiles que conduzia exércitos, quanto da de um possível herói angolano que lutaria no MPLA defendendo a nação recém-liberta da União Nacional para a Independência Total de Angola (UNITA). Ele é descrito alegoricamente "não como o herói de uma guerra sem sentido, não como uma massa aleatória de sangue, carne e alma, mas como um homem que ninguém conheceu nem ninguém viu, que não foi mas poderia ter sido" (ALMEIDA, 2019, p. 58).

O contato de Cartola com Pepe o faz retomar a alegria na relação estabelecida com visíveis tons de homoerotismo:

Um dia, os dois tocados, dançou com Pepe. Afastaram a mesa da sala, agarraram-se um ao outro, Cartola muito hirto e gracioso como um dançarino de salão. Pepe, no gozo, primeiro a imitar um bailarino de flamenco, mas logo compenetrado em manter 
o equilíbrio. A sobriedade que lhes restava foi toda para o cuidado que tinham em que suas caras não se tocassem, apesar de estarem de mãos dadas. [...] A barba de Pepe raspou na sua barba e picou-o. [...] E afastaram-se. [...] Estavam envergonhados, mas contentes (p. 135).

O suicídio de Pepe após a morte do filho, cuja formação passou a ser tecida por ele e Cartola, foi a ruína de seu projeto de vida:

Por isso o menino morto, o seu corpo despedaçado como um jogo de damas deitado ao ar, continha a inconclusão da amizade nova que os unia. Morto Iuri, Cartola e Pepe estavam obrigados a lidar com o horizonte aberto de um livro por escrever. [...] O ânimo da reconstrução tornou-se embaraçoso. Olharam-se como Adão e Eva arrependidos. A fraqueza deles não era não terem estado lá para Iuri, mas terem-se deixado levar pela ideia de que precisavam renascer. [...] Pepe começara por ser uma vírgula na sua vida e tornara-se a justificação da jornada cujo fim naquele instante se revelou. [...] Puseram Pepe no chão e tamparam-no com um lençol. Cartola abraçou-se a ele e então chorou como ainda não tinha chorado em Lisboa. Estendido no pátio com o sapato de fora, Pepe era o seu único amigo, caído por desespero, por vergonha, por remorso - e por amor (ALMEIDA, 2019, p. 190-191).

O final da narrativa retoma a perspectiva cíclica que caracteriza Cartola como o soba descrito no início do livro, agora autocoroado com a cartola nova que comprara trocada por um maço de dinheiro amassado. $\mathrm{O}$ ato de se dirigir na direção do rio Tejo talvez responda à pergunta feita anteriormente na narrativa, sobre se ele conhecia o significado etimológico da palavra Tejo, o qual, como o registro do início da fundação do Estado português, é impreciso. Tejo, recuperamos, pode significar o jogo em que se atiram moedas...

A cartola nova saltava à vista como uma peça deslocada, não por não condizer com o homem, mas por não condizer com o presente. [...] Cartola olhou o Tejo de frente e deulhe uns minutos. [...] E como o rio não suportasse olhá-lo a direito e nem respondesse, desconversando num marulhar ambíguo, o homem tirou a cartola, jogou-a à água e virou as costas (ALMEIDA, 2019, p. 198).

Se o Tejo desconversou diante do olhar desafiante de Cartola, ao lançar nele a sua cartola, Djaimilia pareceu querer nos mostrar, com o gesto, a ressignificação de uma nova trajetória inversa que fará emergir o conceito de civilização como rasura e quebra com a veiculação forjada, em Lisboa, da condição digna aos que se situam na margem de sua sociedade.

\section{Referências}

AGUALUSA, José Eduardo. De princesa a bruxa, $O$ Globo, Rio de Janeiro, p. 6, 25 jan. 2020. Segundo Caderno. 
ALMEIDA, Djaimilia Pereira. Esse cabelo: a tragicomédia de um cabelo crespo que cruza fronteiras. Rio de Janeiro: Leya, 2017. . Luanda, Lisboa, Paraíso. São Paulo: Companhia das Letras, 2019.

CHAVES, Rita. A formação do romance angolano: entre intenções e gestos. São Paulo: Via Atlântica, 1999.

FERREIRA, Eduardo de Sousa. O fim de uma era: o colonialismo português em África. Lisboa: Sá da Costa, 1974.

GABRIEL, Ruan de Sousa. Romance "envolvente" dá a Djaimilia o Oceanos 2019, O Globo, Rio de Janeiro, p. 4, 6 dez. 2019a. Segundo Caderno.

Finalista do Oceanos, escritora portuguesa se inspira em Cartola, $O$ Globo, Rio de Janeiro, p. 6, 5 dez. 2019b. Segundo Caderno.

GRIMAL, Pierre. Dicionário da mitologia grega e romana. Tradução Victor Jabouille. 4. ed. Rio de Janeiro: Bertrand Brasil, 2000.

HUTCHEON, Linda. Poética do pós-modernismo: história, teoria, ficção. Tradução Ricardo Cruz. Rio de Janeiro: Imago, 1991.

LUGARINHO, Mário César. Paradigmas confrontados: algumas masculinidades nas literaturas africanas de língua portuguesa, Metamorfoses, Rio de Janeiro, v. 14, n. 1, p. 141-151, 2017.

PAULO, Heloísa. Aqui também é Portugal: a colónia portuguesa do Brasil e o salazarismo. Coimbra: Quarteto, 2000.

PEPETELA. O tímido e as mulheres. São Paulo: Leya, 2014.

PERRONE-MOISÉS, Leyla. Mutações da literatura no século XXI. São Paulo: Companhia das Letras, 2016.

SARAIVA, José Hermano. História concisa de Portugal. 20 ed. Sintra: Europa-América, 1999.

SCHOLLHAMMER, Karl Erik. Ficção brasileira contemporânea. Rio de Janeiro: Civilização Brasileira, 2011.

\section{Minicurrículo}

Norma Sueli Rosa Lima é professora adjunta do Departamento de Letras da Universidade do Estado do Rio de Janeiro e coordenadora da área de Estudos Literários do Programa de PósGraduação em Letras e Linguística. 